\title{
Energy of adsorption of polar molecules on NaLSX zeolite
}

\author{
Dilnoza Jumaeva ${ }^{1, *}$, Olimjon Toirov ${ }^{2}$, Nigora Rakhmatullaeva ${ }^{3}$ Ravshan Akhmedov ${ }^{1}$, and Izzat Eshmetov ${ }^{1}$ \\ ${ }^{1}$ Institute of General and Inorganic Chemistry of the Academy of Sciences of the Republic of Uzbekistan, Tashkent, 100170, Uzbekistan \\ ${ }^{2}$ Tashkent State Technical University, DSc., Prof. Head of the Department of Electrical machine, Tashkent, 100095, Uzbekistan \\ ${ }^{3}$ Tashkent Institute of Chemical Technology, Tashkent, Uzbekistan
}

\begin{abstract}
The article presents precision data of isotherms and total thermodynamic characteristics, i.e. $\Delta \mathrm{H}$, $\Delta \mathrm{F}$ and $\Delta \mathrm{S}$ of $\mathrm{H}_{2} \mathrm{O}$ adsorption on NaLSX zeolite. The stepwise nature of the change in the heat of adsorption on the studied systems with surface filling is revealed, and the molecular mechanism of water adsorption on NaLSX zeolite in the entire filling area is revealed. It was found that the polar water molecule is adsorbed in the NaLSX zeolite in an amount of $31.8 \mathrm{H}_{2} \mathrm{O} / 1 / 8$ e.u., of which 25.3 are in super cavities, and 6.5 are in $\beta$ cavities.
\end{abstract}

\section{Introduction}

One of the main tasks of colloid chemistry is the study of the number, strength and nature of active centers of dispersed substances, which makes it possible to solve numerous theoretical problems of adsorption and catalysis. Due to the high adsorption and catalytic activity of zeolites, they are widely used in many areas of industry and technology. Among them, first of all, it should be noted deep drying and purification of oil products and natural gas, environmental protection and catalysis.

The unrelenting interest in structural studies of zeolites is stimulated by the fact that they are widely used in chemical technology. The regular structure of zeolites can be easily modified, making it possible to obtain a wide range of adsorbents and catalysts suitable for various reactions. The nature of acidic and basic sites and the distribution of lithium and sodium cations in the zeolite matrix are among the most important problems in surface chemistry.

The authors of [1] synthesized zeolite LSX (Low Silica Type X) by microwave heating. LSX zeolite is synthesized using conventional and microwave heating methods. In both cases, the zeolite is characterized by high crystallinity and purity, a low $\mathrm{Si} / \mathrm{Al}$ molar ratio, and a potassium concentration per unit cell $(\sim 7 \mathrm{wt} . \%)$. It is noted that microwave heating reduces the duration of the synthesis, which is due to the uniformity of heating. Microwave heating also reduces the nucleation and crystallization times. The catalytic properties of the zeolite were tested on the example of the alkylation of toluene with methanol, and no difference was noted in the catalytic properties of both zeolites.

In [2], the adsorption separation of $\mathrm{N}_{2}$ and $\mathrm{A}_{2}$ was carried out by some zeolites in $\mathrm{Li}$ - ion-exchange form with a high degree of exchange. Lithium zeolite types 4A, 13X, and LSX with a high degree of exchange were obtained by the multiple IR method in aqueous solution. IA and output dynamic curves of $\mathrm{N}_{2}$ and $\mathrm{Ar}$ were measured on these zeolites at $25^{\circ} \mathrm{C}$. It was shown that zeolite LiNaA, LiNaX and LiLSX. The study of the adsorption dynamics shows that when using zeolite in an almost completely Li-cation-exchange form, the separation of $\mathrm{N}_{2}$ and $\mathrm{Ar}$ can be carried out in a convenient pressure range. The study of the adsorption dynamics shows that when using zeolite in an almost completely Li-cation-exchange form, the separation of $\mathrm{N}_{2}$ and Ar can be carried out in a convenient pressure range.

For the studied pressure range, the best separation was obtained at a pressure of $0.6 \mathrm{MPa}$, while out of the three studied zeolites, zeolite LiLSX possesses the best separation properties. A study of nitrogen and oxygen adsorption on LSX zeolites has been undertaken [3]. The adsorption of nitrogen and oxygen on zeolites of the LiLSX type in CaLSX at temperatures $\left(-50^{\circ} \mathrm{C}\right), 20^{\circ} \mathrm{C}$, $70^{\circ} \mathrm{C}$ in the pressure range $0.01-1.2,1.5 \mathrm{~atm}$ was studied. Nitrogen adsorption on LiLSX zeolite at all temperatures is about 5-6 times higher than oxygen adsorption. This indicator for the CaLSX zeolite reaches 3. The differential heat of adsorption of nitrogen is approximately $10-12 \mathrm{~kJ} / \mathrm{mol}$ compared to oxygen for CaLSX and decreases for nitrogen in the range 0.01-1 $\mathrm{mmol} / \mathrm{g}$ from $\sim 30$ to $\sim 20 \mathrm{~kJ} / \mathrm{mol}$. mole. For zeolite LiLSX, the heat of nitrogen adsorption falls in the range $0.03-0.6 \mathrm{mmol} / \mathrm{g}$ from $\sim 38$ to $\sim 25 \mathrm{~kJ} / \mathrm{mol}$. For nitrogen, the heat of adsorption is $15-17 \mathrm{~kJ} / \mathrm{mol}$ higher than for oxygen. The activation energies for diffusion of nitrogen and oxygen on LiLSX zeolite are 2-3 times higher than on CaLSX, and are, respectively, 9-10 $\mathrm{kJ} / \mathrm{mol}$ and $2-4 \mathrm{~kJ} / \mathrm{mol}[3]$.

The equilibrium sorption properties of nitrous oxide on type $\mathrm{X}$ zeolite with a low silicon content were established in [4]. The thermodynamic functions of $\mathrm{N}_{2} \mathrm{O}$ sorption on NaLSX and CaLSX zeolites in the form of

\footnotetext{
* Corresponding author: d.jumayeva@list.ru
} 
spherical granules bound by clay are described. Thermodynamic functions were determined from adsorption isosteres and compared with the previously published thermodynamic functions of $\mathrm{CO}_{2}$ adsorption on NaLSX zeolite. Additional information was obtained by simulating adsorption by the Monte Carlo method.

In [5], the vibrational motion frequencies and diffusion coefficients of $\mathrm{N}_{2}$ and $\mathrm{O}_{2}$ adsorbed in LiLSX were determined by the neutron scattering method. Measurements were carried out for the same component at $260 \mathrm{~K}$ with different fillings. The experimental value of the longitudinal frequency $\mathrm{N}_{2}$ in the interaction with Li cations is compared with the results of quantum chemical calculations. According to the data of quasielastic neutron scattering, $\mathrm{O}_{2}$ diffusion occurs faster than $\mathrm{N}_{2}$. The Darken approximation turns out to be inaccurate, with the corrected values of the diffusion coefficients $\mathrm{N}_{2}$ and $\mathrm{O}_{2}$ decreasing with increasing filling.

The crystal structures of faujasite types of dehydrated LSX zeolites with two different degrees of Li exchange $85 \%$ and $100 \%$ were studied at room temperature by neutron powder diffraction [6]. Both structures were purified in the space group $\mathrm{Fd}^{3}$ and were alternating (Si) silicon and - (Al) aluminum lattice tetrahedra. All extralattice cations have been detected.

Partially mixed zeolite LSX (Low silica X) with the composition $\mathrm{Li}_{82} \mathrm{Na}_{14} \mathrm{Si}_{96} \mathrm{Al}_{96} \mathrm{O}_{384}, \mathrm{a}=24.6845$ (1) $\AA$, has the following location: center $\mathrm{I}^{\prime}=32 \mathrm{Li}$, center II $=32$ $\mathrm{Li}$, center III $=18 \mathrm{Na}$. A fully substituted LSX zeolite with the composition $\mathrm{Li}_{95} \mathrm{NaSi}_{96} \mathrm{Al}_{96} \mathrm{O}_{384}, \mathrm{a}=24.6845$ (1) $\AA$, has the following location: center $\mathrm{I}^{\top}=32 \mathrm{Li}, \mathrm{II}=32$ $\mathrm{Li}, \mathrm{III}=15 \mathrm{Li}$ and $\mathrm{III}=16 \mathrm{Li}$.

The study of the authors of [7] is devoted to the comparison of the 170 NMR spectra of zeolites of the LTA and LSX types. A comparative study of ${ }^{17} \mathrm{O}$ NMR of various cation-exchange zeolites of the LTA and LSX types was carried out. LSX samples containing divalent cations contain resonances with close chemical shifts relative to the spectra previously assigned to "bare" framework oxygen atoms in the Ca-LTA and Sr-LTA systems. The data are consistent with trends in the spectra of LTA and LSX type zeolites with monovalent cations, which show an increase in the average chemical shift with increasing cation radius. The spectrum of $\mathrm{Li}$ LSX, like Na-LSX, can be attributed to the T-O-T bond angles. The study of gas sorption on Li-LSX facilitates the identification of framework oxygen atoms forming $\beta$ cavities and demonstrates the sensitivity of ${ }^{17} \mathrm{O}$ shifts to gas adsorption.

The authors of [8] studied the adsorption of nitrogen and oxygen on industrial zeolites $\mathrm{NaX}, \mathrm{CaE}$ and LiLSX. At a temperature of $773 \mathrm{~K}$ and pressures up to $100 \mathrm{kPa}$, nitrogen adsorption isotherms were measured, and on the basis of the theory of volumetric filling of micropores using the condition of linearity of isosteres, the calculations of nitrogen and oxygen adsorption at a temperature of $293 \mathrm{~K}$ and pressures up to $10 \mathrm{MPa}$ are given. The obtained isotherms satisfactorily describe the data obtained experimentally.

Zeolites of the LSX type are interesting objects for scientific research: they are porous bodies characterized by a specific skeletal structure and regular geometry of pores (intracrystalline cavities and channels). An important feature of zeolites is the ability to vary the chemical composition of crystals and the geometric parameters (shape and size) of intracrystalline pores, i.e. the possibility of their structural and chemical modification, which can be carried out either by varying the conditions for direct synthesis of zeolites, or by changing the chemical composition of zeolite crystals of the same structural type. This fact makes zeolites very convenient objects for studying adsorption equilibria, the nature of adsorption interactions, the mechanism and kinetics of catalytic reactions, molecular sieve effects, and diffusion of molecules in fine pores of controlled sizes [9].

For 20 years, zeolites have been used in industry for air purification using PSA (pressure swing adsorption) [10]. The nitrogen adsorption capacity of LSX correlates with the amount of positively charged $\mathrm{Li}$ cations. Zeolites LiX and LiY are widely used as catalysts for isomerization of olefins [11]. In [12], the dispersal of Li cations in a zeolite matrix was determined. For this, classical diffraction methods are used, especially for single crystals. However, obtaining a single crystal of zeolite is difficult and therefore, mainly, the method of $\mathrm{X}$-ray diffraction of powders is used.

Refinement of the results obtained on the basis of these methods is time-consuming. There is another problem - the presence of mobile cations and molecules in zeolites. Since Li cations contain only two effective electrons, the neutron diffraction technique should be used to study it instead of X-ray analysis.

It is also advisable to use the solid state NMR technique. For example, recently, using 23Na MAS and DOR NMR spectroscopy [13], the location of six components related to different crystallographic positions of $\mathrm{Na}$ cations was studied. Forano and colleagues [14] published the first results on the characterization of Li cations in anhydrous LiX zeolite $(\mathrm{Si} / \mathrm{Al}=1.25)$. It was found that the cations are located in three positions in the $\beta$ - and super cavities.

SI Vratislav and colleagues [15] studied the structure of NaLSX. The reaction of methyl iodide with $\mathrm{Na}$ cations was used to obtain anchor methyl groups in the zeolite structure, which was monitored by 13C MAS NMR spectroscopy. Samples of neutron diffraction were obtained at 298 and $723 \mathrm{~K}$ on a KSN - 2 diffract meter, which was placed in a research reactor LVR - 15. All structural parameters of the samples were given in $[1-2$, 16]. The following authors [17-21] have dealt with the issues of energy, electrical mechanisms and the energy of adsorption of the adsorbent.

Purpose of the work: Investigation of the energy and mechanism of adsorption of polar molecules on NaLSX zeolite.

\section{Research methods}

We carried out adsorption studies on NaLSX zeolite. The unit cell composition of the NaLSX zeolite is $\mathrm{Na}_{96} \mathrm{Si}_{96} \mathrm{Al}_{96} \mathrm{O}_{384}$. Before the start of the experiment, the adsorbent was pumped out at $723 \mathrm{~K}$ for 10 hours to a 
high vacuum $\left(10^{-3} \mathrm{~Pa}\right)$. The adsorption-calorimetric method used in this work allows one to obtain highprecision molar thermodynamic characteristics, as well as to reveal the detailed mechanisms of adsorption processes occurring on adsorbents and catalysts. Adsorption measurements and dosage of adsorbate were carried out using a universal high-vacuum adsorption unit, in the working section of which exclusively mercury gates were used, replacing lubricated taps. The installation allows for dosage of the adsorbate both by gas-volumetric and volumetric-liquid methods. A modified DAK 1-1 calorimeter with high accuracy and stability was used as a calorimeter. To study the adsorption properties of zeolites, water was chosen as the adsorptive.

The adsorption of water in microporous zeolites is of great scientific and technical interest due to the widespread use of zeolites as catalysts, adsorbents for drying, purification, and separation of gases and liquids [22].

The behavior of water in the structure of zeolites was studied by various methods [16, 23]. In dehydrated zeolites, exchangeable cations that compensate for the negative charge of alumino-oxygen tetrahedra are localized in certain energetically favorable positions of the adsorbent structure. One of the main methods for diagnosing the structure of crystalline adsorbents is $\mathrm{X}$ ray diffraction.

Using this method, one can obtain information on the localization of cations in the structure of the adsorbent. However, it is not suitable for studying the host/guest interaction in the $\mathrm{H}_{2} \mathrm{O} / \mathrm{NaLSX}$ adsorption system, since $\mathrm{Na}$ differs little from $\mathrm{H}_{2} \mathrm{O}$ in the number of electrons, and therefore it is difficult to distinguish them. The only alternative to this method is the adsorption calorimetry method, which provides detailed information on the formation of ion / molecular complexes in the zeolite matrix in a wide range of fillings, ranging from zero values to saturation. Zeolite NaLSX is a new faujasite type zeolite with $\mathrm{Si} / \mathrm{Al}=1$. Until recently, the studied zeolites had $\mathrm{Si} / \mathrm{Al}>1.09$. According to [6], the distribution of cations in the zeolite structure is as follows: 4 cations per $1 / 8$ of the unit cell ( $1 / 8$ e.u.) are located in the $\mathrm{S}_{\mathrm{I}}$ position (in the six-membered rings connecting cuboctahedra and hexagonal prisms), 4 cations per $1 / 8$ e.i. are located in the $\mathrm{S}_{\text {II }}$ position (in sixmembered rings connecting cuboctahedrons and large cavities) and the remaining 4 cations at $1 / 8$ e.u. are located in position $\mathrm{S}_{\mathrm{III}}$ (at the four-membered rings of the large cavity). In total, there are 12 cations per $1 / 8$ e.u., or the super cavity, or 96 cations per unit cell. As seen from the composition, zeolites have a very high charge density. Figure 1 shows the adsorption isotherm (a) of water in NaLSX zeolite. The isotherm does not change smoothly with increasing pressure, but has kinks, each of which reflects the transition from the adsorption of one type of centers to another.

It is known [24] that adsorption on microporous zeolites proceeds according to the bulk filling mechanism. Using the provisions of the theory of Polyany and generalizing a large experimental material, Dubinin M.M. with colleagues came to the conclusion about the possibility of using the Weibul distribution function as the distribution function of the adsorption volume over the value of the potential for describing adsorption on microporous adsorbents.

With regard to the distribution of the degree of filling over the adsorption potential, the Weibull distribution function is represented by the ratio:

$$
\Theta=\exp [-(\mathrm{A} / \mathrm{E}) \mathrm{n}]
$$

Where, $\mathrm{E}$ and $\mathrm{n}$ are parameters independent of temperature.

The value of $\mathrm{E}$ is called the characteristic adsorption energy. The exponent $\mathrm{n}$ is expressed in integers from 1 to 6 , depending on the structure of the adsorbent. $\mathrm{A}$ is the work of adsorption, i.e. the work of transferring 1 mol of gas from the surface of a liquid adsorbate (pressure $\mathrm{P}^{\circ}$ ) into an equilibrium gas phase (pressure $\mathrm{P}$ ):

$$
\mathrm{A}=\mathrm{RT} \ln \left(\mathrm{P} / \mathrm{P}^{\circ}\right)
$$

The degree of adsorbent filling can be represented as the ratio of the adsorption value a to the maximum adsorption a0. Then from equation (1) we get:

$$
\mathrm{a}=\mathrm{a} 0 \exp [-(\mathrm{A} / \mathrm{E} 0)] \mathrm{n}
$$

In [24], the possibility of a complete description of the isotherm was shown using the polynomial equation of TOZM (up to $3^{\mathrm{x}}$ ).

\section{Results and discussion}

We were able to fully describe the isotherm of water adsorption on NaLSX zeolite with a three-term equation:

$$
\begin{aligned}
& a=9.59 \exp [-A / 30.11) 4]+ \\
& +5.53 \exp [-A / 15.15) 6]+3.98 \exp [-A / 5.98) 2]
\end{aligned}
$$

where, $\mathrm{a}$ is the adsorption value in $\mathrm{mmol} / \mathrm{g}, \mathrm{A}=\mathrm{RT} \ln$ $\left(\mathrm{P} / \mathrm{P}^{\circ}\right)$ is the adsorption work in $\mathrm{kJ} / \mathrm{mol}$. For the water NaLSX system, the parameters of the equation for the first term are: $\mathrm{a} 01=9.59 \mathrm{mmol} / \mathrm{g}, \mathrm{E} 01=30.11 \mathrm{~kJ} / \mathrm{mol}$ and $\mathrm{n} 1=4$; for the second term a02 $=5.53 \mathrm{mmol} / \mathrm{g}$, $\mathrm{E} 02=15.15 \mathrm{~kJ} / \mathrm{mol}$ and $\mathrm{n} 2=6$; and for the third term $\mathrm{a} 03=3.98 \mathrm{mmol} / \mathrm{g}, \mathrm{E} 03=5.98 \mathrm{~kJ} / \mathrm{mol}$ and $\mathrm{n}_{3}=2$.

The most subtle information on ion-molecular interactions is provided by the differential heats of adsorption $\left(\mathrm{Q}_{\mathrm{d}}\right)$ of water in the NaLSX zeolite (Fig. 2). The curve has a pronounced stepwise character, where each step stoichiometrically reflects the formation of multidimensional cation-water complexes with cations located in different crystallographic positions.

The following segments can be distinguished on the $\mathrm{Q}_{\mathrm{d}}$ curve: the first, where $\mathrm{a}=0-2.69 \mathrm{mmol} / \mathrm{g}$, and the heat $\mathrm{Q}_{\mathrm{d}}$ varies from 91 to $80,3 \mathrm{~kJ} / \mathrm{mol}$; the second - $\mathrm{a}=$ $2.69-5.13 \mathrm{mmol} / \mathrm{g}, \mathrm{Q}_{\mathrm{d}}=80.3-67 \mathrm{~kJ} / \mathrm{mol}$; third - $\mathrm{a}=$ 5.13 - $7.54 \mathrm{mmol} / \mathrm{g}, \mathrm{Q}_{\mathrm{d}}=\sim 68 \mathrm{~kJ} / \mathrm{mol}$; fourth - $\mathrm{a}=7.54$ $9.87 \mathrm{mmol} / \mathrm{g}, \mathrm{Q}_{\mathrm{d}}=\sim 69 \mathrm{~kJ} / \mathrm{mol}$; fifth $-\mathrm{a}=9.87-13.58$ $\mathrm{mmol} / \mathrm{g}, \mathrm{Q}_{\mathrm{d}}=\sim 70 \mathrm{~kJ} / \mathrm{mol}$; sixth - $\mathrm{a}=13.58-17.32$ $\mathrm{mmol} / \mathrm{g}, \mathrm{Q}_{\mathrm{d}}=67.5-55.5 \mathrm{~kJ} / \mathrm{mol}$; and, finally, the seventh $-\mathrm{a}=17.32-18.69 \mathrm{mmol} / \mathrm{g}, \mathrm{Q}_{\mathrm{d}}=55.5-46.6 \mathrm{~kJ} /$ mol. 
The segments showed generally correlate well with the number of cations in different crystallographic positions. A difference was observed in the case of adsorption on cations in the $\mathrm{S}_{\text {III }}$ and $\mathrm{S}_{\mathrm{I}}$ positions. Instead of 4 molecules $\mathrm{H}_{2} \mathrm{O} / 1 / 8$ e.i. 4.6 water molecules are adsorbed on $\mathrm{S}_{\mathrm{III}}$; therefore, the number of cations in the SI' position should be less. The number of cations in the $\mathrm{S}_{\text {II }}$ position exactly corresponds to the number indicated in [6].

Further, adsorption occurs on the same cations with the formation of multidimensional cation / water complexes. In total, 31.8 water molecules are adsorbed per $1 / 8$ of the unit cell, of which 25.3 are in supercavities, 6.5 in $\beta$-cavities.

Using the precision values of differential heats of adsorption and adsorption isotherms, we calculated the differential molar entropy of adsorption $\left(\Delta \mathrm{S}_{\mathrm{d}}\right)$ of water on NaLSX (Fig. 3). The calculated data are plotted against the entropy of liquid water. In accordance with the stepped $\mathrm{Q}_{\mathrm{d}}$ curve, the adsorption entropy curve has a polyextremal form. Each step has its own partial entropy of adsorption. The average molar integral entropy of water adsorption in the cavities of the NaLSX zeolite is $20.28 \mathrm{~J} / \mathrm{mol}^{*} \mathrm{~K}$.

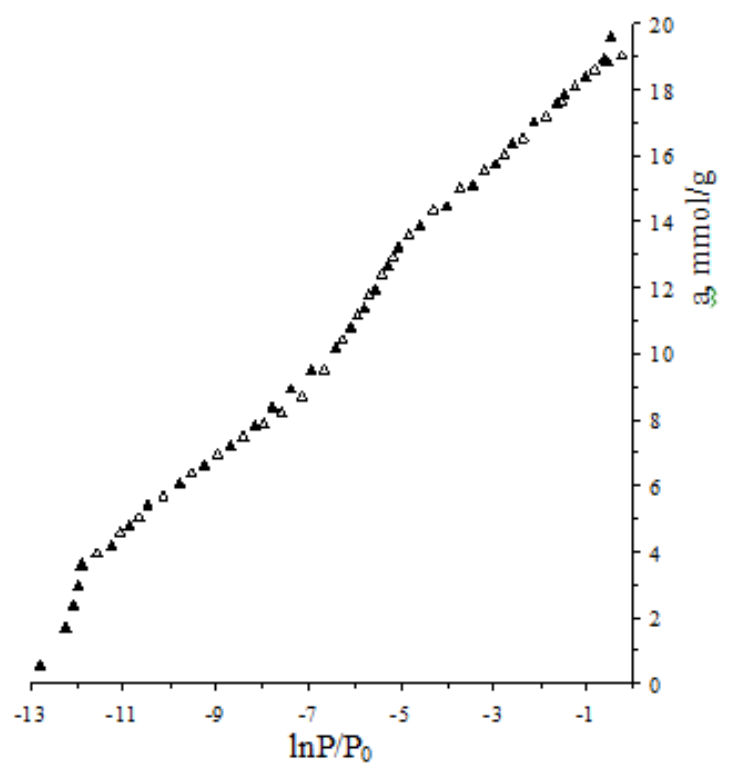

Fig. 1. Isotherm of $\mathrm{H}_{2} \mathrm{O}$ adsorption on $\mathrm{NaLSX}$ zeolite at $303 \mathrm{~K}$.

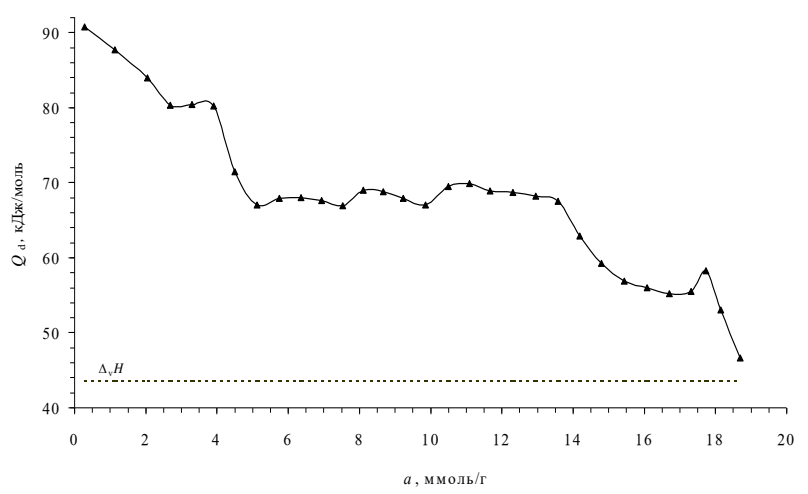

Fig. 2. Differential heats of adsorption of $\mathrm{H}_{2} \mathrm{O}$ in $\mathrm{NaLSX}$ zeolite at $303 \mathrm{~K}$. Horizontal dashed line - heat of condensation of $\mathrm{H}_{2} \mathrm{O}$ at $303 \mathrm{~K}$.

This value indicates the hindered state of water molecules in the matrix zeolite is close to the mobility in crystalline water (in this diagram, the entropy of ice is $\left.26 \mathrm{~J} / \mathrm{mol}^{*} \mathrm{~K}\right)$. Figure 4 . the dependence of the time of establishment of adsorption equilibrium $(\tau)$ on the filling of the zeolite with water is presented. At low fillings, equilibrium is established in more than 10 hours. With increasing pressure, the adsorption process is accelerated, and equilibrium is reached in $\sim 2$ hours. The slowdown in adsorption in the range from 2.69 to 5.13 $\mathrm{mmol} / \mathrm{g}$ is due to the difficulty of penetrating water molecules into the $\beta$-cavity. The size of the 6 -membered oxygen windows entering the $\beta$-cavity is $2.6-2.8 \AA[22$ 25].

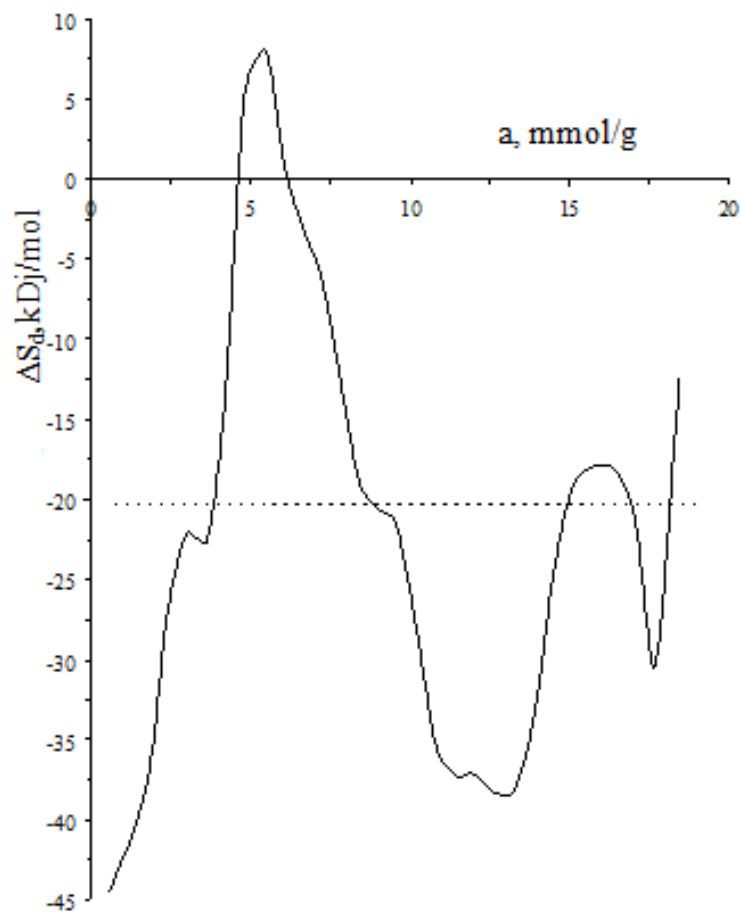

Fig. 3. Differential molar entropies of $\mathrm{H}_{2} \mathrm{O}$ adsorption in NaLSX zeolite at $303 \mathrm{~K}$. Horizontal dashed line - mean integral entropy. The entropy of liquid $\mathrm{H}_{2} \mathrm{O}$ is taken to be zero. 


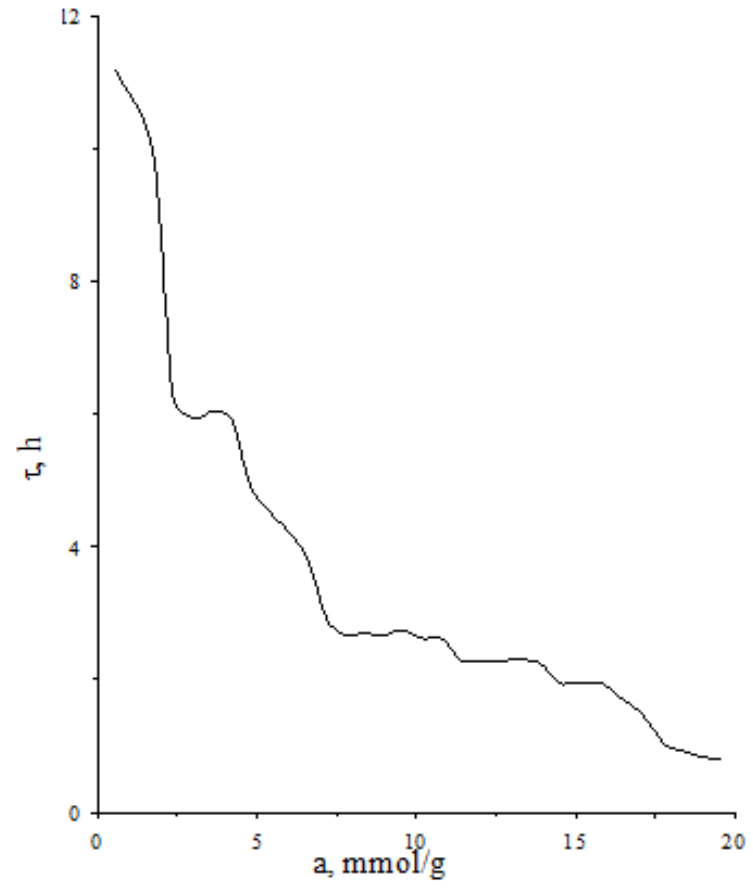

Fig. 4. The time to establish adsorption equilibrium depending on the amount of water adsorption in NaLSX zeolite at $303 \mathrm{~K}$.

\section{Conclusion}

The stepwise nature of the change in the heat of adsorption on the studied systems with surface filling is revealed, and the molecular mechanism of water adsorption on NaLSX zeolite in the entire filling area is revealed. It was found that the polar water molecule is adsorbed in the NaLSX zeolite in an amount of 31.8 $\mathrm{H}_{2} \mathrm{O} / 1 / 8$ e.u., of which 25.3 are in super cavities, and 6.5 are in $\beta$-cavities.

\section{References}

1. S. Vratislav, M. Dlouha, V. Bosaček, Chemisorbed methyl groups in $\mathrm{NaX}$ and $\mathrm{NaY}$ types of zeolitic catalysts, Physica B, 276-278, 929-931 (2000)

2. M. Dlouha, S. Vratislav, V. Bosaček, The Study of structural features of phase transitions in $\mathrm{N}(\mathrm{H} / \mathrm{D}) 4 \mathrm{SCN}$ (the monoclinic phase) by neutron scattering, Crystallography reports, 43 (2), 202210 (1998)

3. Jumayeva Dilnoza, Eshmetov Izzat, Jumabaev Berdah, Agzamkhodjayev Anvarkhodja, Carbon adsorbents on the basis of Brown coal of Angren for cleaning industrial wastewater, Journal of Chemical Technology and Metallurgy, 51 (2), 210-214 (2016)

4. Hua Jiang, Bi-Ying Zhao, You-Chang Xie, Influence of water on adsorption properties of lithium exchanged low silica $\mathrm{X}$ zeolite, Wuli Huaxue xuebao Acta Phys. Chim. Sin., 18 (7), 577-580 (2002)

5. Martin Bülow, Dongmin Shen, S.R. Jale, Sorption equilibrium properties of nitrous oxide on low - silicon $\mathrm{X}$ - type zeolites, Colloid and surfaces, A., 241 (1-3), 59-65 (2004)

6. Herve Jobic, Helmut Schober, Pluton Pullumbi, Adsorption and diffusion of $\mathrm{N}_{2}$ and $\mathrm{O}_{2}$ in LiLSX studied by neutron scattering techniques, 8 International Conference on Fundamentals of Adsorption (FOA8), Sedona, Ariz., Adsorption, 11, 449-454 (23-28 May 2004)

7. J. Plevert, F. Di Renzo, G. Chiari, Cation positions in dehydrated zeolites $\mathrm{Li}-\mathrm{LSX}$ and Li, $\mathrm{Na}$ - LSX, 12 th International Zeolite Conference, Materials Research Society, 135-139 (1999)

8. J.E. Readman, C.P. Grey, M. Ziliox, L.M. Bull, Samason Ago, Comparison of the 170 NMR spectra of zeolites LTA and LSX, Symposium "Recent Advances and applications of Solid State NMR from Superconducting Physics to Molecular Biology", Warwick, Solid State Nucl. Magn. Reson., 26 (3-4), 153-159 (14 September 2004)

9. D.J. Jumaeva, I.D. Eshmetov, A.A. Agzamkhodjaev, Adsorption treatment and mitigation of industrial wastewater by coal adsorbents, Journal of Chemical Industry, Russia, Moscow, 91 (3), 150-154 (2014)

10. MF.Jr. Hochella, Atomic structure, micro topography, composition, and of mineral surfaces, In: MF.Jr. Hochella, A.E. White editors, Mineralwater interface geochemistry, Washington, DC: Mineral Soc Am., 87-132 (1990)

11. T.R. Gaffney, Porous solids for air separation, Solid State \& Mater. Science, 1, 69-75 (1996)

12. K. Pitchumani, M. Hunger, G. Engelhardt, Amoureux J/P, Solid state NMR., 7, 95 (1996)

13. M. Feuerstein, R.F. Lobo, Characterization of the Li cations in zeolite LiLSX by Solid State NMR and neutron diffraction, J. Am.Chem. Soc., 115, 7833 (1993)

14. M. Feuerstein, G. Hunger, J.P. Engelhardt, Characterization of sodium cations in dehydrated zeolite NaX by $23 \mathrm{Na}$ NMR spectroscopy, Solid state NMR, 7, 95 (1996)

15. C. Frano, R.C.T. Slade, E. Krogh Anderson, I.J. Krogh Anderson, E. Prince, Neutron diffraction of full structures of anhydrous U-X and Li-Y zeolites, J. Solid State Chem., 82, 95-102 (1989)

16. S. Vratislav, M. Dlouha, V. Bosaček, Location of chemisorbed methylium ions in zeolites by neutron diffraction end 13C MAS NMR, Applied Physics A, 74, 6-8 (2002)

17. D. Bystrov, T. Olimjon, M. Gulzoda, Y. Dilfuza, NISS2020: Proceedings of the 3rd International Conference on Networking, Information Systems \& Security, 54, 1-3 (2020) DOI: $10.1145 / 3386723.3387873$

18. D. Bystrov, T. Olimjon, G. Sanjar, T. Mirzokhid, U. Sardor, NISS2020: Proceedings of the 3rd International Conference on Networking, Information Systems \& Security, 49, 1-4 (2020) DOI: $10.1145 / 3386723.3387868$ 
19. O. Toirov, A. Bekishev, S. Urakov, U. Mirkhonov, E3S Web of Conferences, 216, 01116 (2020) DOI: 10.1051/e3sconf/202021601116

20. O. Toirov, K. Alimkhodjaev, N. Pirmatov, A. Kholbutaeva, E3S Web of Conferences, 216, 01119 (2020) DOI: 10.1051/e3sconf/202021601119

21. H. Afrisal, B. Setiyono, M.F. Yusuf, R.M. Suin, O. Toirov, 2020 7th International Conference on Information Technology, Computer, and Electrical Engineering (ICITACEE), 41-46 (2020)

DOI: 10.1109/ICITACEE50144.2020.9239228

22. L. Bertsch, H.W. Habgood, An infrared spectroscopic study of the adsorption of water and carbon dioxide by Linde Molecular sieve, $\mathrm{X}$. J. Phys. Chem., 67, 1621-1628 (1963)

23. C.L. Angell, P.C. Schaffer, Infrared spectroscopic investigations of zeolite and adsorbed molecules, J. Phys. Chem., 69, 3463-3470 (1965)

24. M.M. Dubinin, Adsorption and porosity (M., 2002)

25. D. Jumaeva, I. Eshmetov, B. Jumabaev, A. Agzamkhodjaev, Coal adsorbents for sewage treatment, European Conference on Innovations in Technical and Natural Sciences, Austria, Vena, 104-109 (2015) 